\title{
BMJ Open Association between physical activity and health-related quality of life in elderly individuals with pre-diabetes in rural Hunan Province, China: a cross- sectional study
}

\author{
Huilan Xu, ${ }^{1}$ Lu Tang, ${ }^{1}$ Zhao Hu, ${ }^{1}$ Fan Gao, ${ }^{1}$ Yang Yang, ${ }^{1}$ Lulu Qin, ${ }^{2}$ Bang-an Luo ${ }^{3}$
}

To cite: $\mathrm{Xu} \mathrm{H}$, Tang L, Hu Z, et al. Association between physical activity and healthrelated quality of life in elderly individuals with pre-diabetes in rural Hunan Province, China: a cross-sectional study. BMJ Open 2018;8:e019836. doi:10.1136/ bmjopen-2017-019836

- Prepublication history for this paper is available online. To view these files, please visit the journal online (http://dx.doi. org/10.1136/bmjopen-2017019836).

HX and LT contributed equally.

Received 29 September 2017 Revised 28 December 2017 Accepted 15 January 2018
Check for updates

${ }^{1}$ Department of Social Medicine and Health Management, Xiangya School of Public Health, Central South University, Changsha, China

${ }^{2}$ Department of Social Medicine and Health Management, School of Medicine, Hunan Normal University, Changsha, China ${ }^{3}$ Department of Mental Health, Brain Hospital of Hunan Province, Changsha, China

Correspondence to

Dr Lulu Qin;

powerestlulu@163.com

\section{ABSTRACT}

Objectives There are few data on the relationship between health-related quality of life (HRQoL) and physical activity among elderly individuals with pre-diabetes. This study aimed to determine if differences existed in HRQoL between individuals with pre-diabetes who were physically active compared with those who were physically inactive in rural China.

Design, setting and participants $A$ cross-sectional survey was conducted among the elderly ( $\geqq 60$ years) in rural communities in Yiyang City of China. Multistage cluster random sampling was carried out to select 42 areas, and interviews were conducted among 434 elderly individuals with pre-diabetes. Pre-diabetes was screened using an oral glucose tolerance test.

Main outcome measures The Medical Outcomes Study 36-Item Short Form Health Survey questionnaire was used to measure HRQoL. Physical activity was assessed using the International Physical Activity Questionnaire. Multivariate analysis of covariance (MANCOVA) was used to test for differences in HRQOL between the physically active group and the inactive group.

Results A total of 434 individuals with pre-diabetes were included in this study. The physical component summary (PCS) score of HRQoL was $42.1 \pm 10.2$ and the mental component summary score was $46.4 \pm 8.9$. A median total physical activity of 524 metabolic equivalent-min/ week was reported. A significant MANCOVA model (Wilks' $\lambda=0.962, F(2,423)=8.44, P<0.001)$ indicated that elderly individuals with pre-diabetes who were physically active reported higher PCS scores $\left(\mathrm{M}_{\text {diff }}=5.2, \mathrm{P}<0.001\right.$, effective size $=0.47$ ) compared with those physically inactive after adjusting for the following covariates: age, gender, marital status, education, smoking, chronic disease, body mass index and waist:hip ratio.

Conclusions The HRQoL of elderly individuals with pre-diabetes is poor in rural China. These findings demonstrated that elderly individuals with pre-diabetes who were physically active had higher PCS scores than those who were physically inactive. Furthermore, these results support the rationale for developing a physical activity intervention for HRQoL of individuals with prediabetes.

Trial registration number ChiCTR-IOR-15007033; Results.
Strengths and limitations of this study

- This is the first study to examine the association between health-related quality of life (HRQoL) and physical activity among elderly individuals with pre-diabetes in rural China.

- The association between HRQoL and physical activity is analysed both from the physical component summary score and the mental component summary score, making the results more accurate and comprehensive.

- The International Physical Activity Questionnairelong version and the Medical Outcomes Study 36item Short Form Health Survey questionnaire are proven to be suitable for assessment in the elderly ( $\geqq 60$ years) in China, making the results of the study generalisable.

- The cross-sectional study design makes causal relationships indeterminable.

The study is limited by its self-reported design.

\section{INTRODUCTION}

Pre-diabetes describes individuals who have impaired fasting glucose (IFG) and/or impaired glucose tolerance (IGT). ${ }^{1}$ Many studies have identified that people with pre-diabetes have a high risk of developing diabetes, and the occurrence increases with age. $^{23}$ In China, it has been estimated that more than 148.2 million adults have pre-diabetes and more than $20 \%$ of the elderly have pre-diabetes, both in rural and urban areas. ${ }^{4}$ However, several trials have demonstrated that pre-diabetes can be inverted to normal plasma glucose levels, and that the risk of developing diabetes decreases after a diet and physical activity lifestyle intervention. ${ }^{56}$

Health-related quality of life (HRQoL) is a comprehensive and multidimensional condition that includes physical, emotional and social functions. ${ }^{78}$ Many studies have found that both sociodemographic and lifestyle 
factors are related to HRQoL. ${ }^{9-11}$ Studies also found that the HRQoL scores were relatively lower among individuals with IGT compared with the healthy population; besides, individuals progressing to pre-diabetes or diabetes experienced a greater loss in HRQoL than people with persistent normal glucose tolerance. ${ }^{12-14}$ Thus, assessing the HRQoL enables us to investigate its influencing factors, and consequently create interventions to improve it, especially by relieving pain, malaise and consequences of diseases. ${ }^{1516}$

Several studies have shown that active physical activity had a positive effect on both the physical and mental domains of HRQoL among patients with diabetes and the elderly. ${ }^{17-19}$ A systematic review demonstrated a positive association between physical activity and HRQoL in a general adult population..$^{20}$ Many studies have reported that physical activity intervention can significantly improve the quality of life in clinical and healthy populations. ${ }^{21-23}$ Furthermore, a study reported higher scores on HRQoL in overweight and obese individuals who were in an action stage of change for exercise compared with those in a precontemplation stage. ${ }^{24}$ However, there are few studies in the literature that have evaluated the influence of physical activity on HRQoL among elderly individuals with pre-diabetes. Moreover, there is still a paucity of published studies on HRQoL among elderly individuals with pre-diabetes in rural areas in China.

Therefore, the aim of our study was to investigate the situation of HRQoL and physical activity among the elderly with pre-diabetes in rural areas. Moreover, we intended to explore the association between physical activity and HRQoL. We hypothesised that elderly individuals with pre-diabetes who were physically active would report higher HRQoL scores than those who were physically inactive.

\section{METHODS}

\section{Study design}

This was a cross-sectional study that was carried out in the rural areas of Yiyang City of Hunan Province in China between April and July 2015. This study was registered at the Chinese Clinical Trial Registry (trial registration number: ChiCTR-IOR-15007033). All participants signed the respective consent forms.

\section{Sample size}

Sample size was calculated using the formula for cross-sectional studies as follows:

$$
N=\frac{Z_{1-\alpha / 2}^{2} p(1-p)}{d^{2}}
$$

where $Z_{1-\alpha / 2}=1.96$ when $\alpha=0.05, p$ is the prevalence of pre-diabetes (which was $20 \%$ in this study), and $d$ is admissible error (which was $4 \%$ here). According to the formula, the theoretical sample size was 423 , which included an extra $10 \%$ to allow for subjects lost during the study. Our initial investigation revealed there were about 10 elderly subjects with pre-diabetes in each village, so a total of 42 villages were required.

\section{Study population and procedures}

The subjects in this study were aged 60 years and over and were from the rural areas of Yiyang City of Hunan Province. To select a representative sample of elderly population with pre-diabetes, a screening programme was carried out in the elderly population in Yiyang City. A multistage cluster randomised sampling method was used. In the first stage, two out of six counties were selected according to geographical characteristics. In the second stage, 2 (Yangluozhou and Yinfengqiao) out of 11 townships and 2 (Qingshuzui and Maocaojie) out of 9 townships were randomly selected. In the third stage, $25 \%$ of the rural villages were randomly selected from each chosen township (each township contains $30-50$ villages). In the final stage, all households in each selected village with elderly individuals who had lived in the area for 3 years or longer were eligible to participate in the screening programme. Those with severe physical and mental illness were excluded from the screening. Participants diagnosed as having pre-diabetes using oral glucose tolerance test (OGTT) were enrolled in this study. After overnight fasting of at least 10 hours and no breakfast, the participant's venous blood was sampled into a vacuum tube and stored at $-80^{\circ} \mathrm{C}$ for no more than 1 hour to analyse fasting blood glucose. Next, each participant consumed a standard $75 \mathrm{~g}$ glucose solution and the venous blood was sampled again 2 hours later to measure the 2-hour postglucose load. The level of plasma glucose was measured using the hexokinase enzymatic method. The diagnostic standards for pre-diabetes as stated in the 1999 WHO criteria $^{1}$ were applied, and subjects were categorised into the following three groups: (1) an IFG group with fasting plasma glucose of $6.1-7.0 \mathrm{mmol} / \mathrm{L}$ and a 2-hour postglucose load of $<7.8 \mathrm{mmol} / \mathrm{L}$; (2) an IGT group with a 2-hour postglucose load of 7.8-11.1 mmol/L and fasting plasma glucose of $\leq 6.1 \mathrm{mmol} / \mathrm{L}$; and (3) an IFG+IGT group.

More details of the study design and the pre-diabetes screening procedure have been described elsewhere. ${ }^{25}$ In brief, 2144 elderly individuals took part in the pre-diabetes screening programme and completed the OGTT, and in total 461 elderly individuals had pre-diabetes. For various reasons, 21 of those with pre-diabetes had no response, and the response rate was $95.4 \%$. Six more had incomplete data. Finally, a total of 434 individuals with pre-diabetes from 42 villages were included in this study.

\section{Data collection and measurements \\ Sociodemographic information}

Sociodemographic information was collected by trained staff using a set of structured questionnaires, which included age, gender, marital status, education, history of hyperglycaemia, family history of diabetes, chronic disease, smoking and alcohol drinking. Marital status was classified as married or non-married. Non-married 
status included divorce, never married, losing a partner and living together without a marriage certificate. Family history of diabetes was defined as being present in subjects whose first-degree relatives were diabetic. Education was assessed by asking the participants to select their highest level of education from the following choices: less than 1 year, 1-6 years and 6 years and above. History of hyperglycaemia was defined as a situation of fasting glucose $>6.1 \mathrm{mmol} / \mathrm{L}$ or 2-hour glucose $>7.8 \mathrm{mmol} / \mathrm{L}$ without a diagnosis of diabetes, which was measured in other places before the interview. Smoking was defined as averaging one or more cigarettes in the last year. Alcohol drinking was defined as drinking a glass of wine (approximately $250 \mathrm{~mL}$ beer or $100 \mathrm{~mL}$ sake or $20 \mathrm{~mL}$ liquor). Chronic diseases included hypertension, coronary heart disease, dyslipidaemia and others.

\section{Anthropometric measurements}

Anthropometric measurements included height, weight, blood pressure, waist circumference and hip circumference. The standing height of the participants without shoes was measured using a portable stadiometer and recorded to the nearest $0.1 \mathrm{~cm}$. The weight of the participants with light clothing and without shoes was measured to the nearest $0.1 \mathrm{~kg}$ using a digital scale. Body mass index (BMI) was calculated using the formula of weight in kilogram divided by height in $\mathrm{m}^{2}\left(\mathrm{~kg} / \mathrm{m}^{2}\right)$. The current Chinese standard classification states that the cut-off values for normal weight, overweight and obesity BMI are $18.5 \mathrm{~kg} / \mathrm{m}^{2}, 24.0 \mathrm{~kg} / \mathrm{m}^{2}$ and $28.0 \mathrm{~kg} / \mathrm{m}^{2}$, respectively. ${ }^{26}$ Blood pressure included systolic and diastolic pressure and was assessed twice (2 min apart) using an electronic blood pressure monitor (LifeSource UA-767PV, A\&D Medical, San Jose, California, USA) after the participant had been seated for at least $5 \mathrm{~min}$ in a quiet room. The two blood pressure readings were averaged to use for analysis. Hypertension was defined as systolic blood pressure $\geq 140 \mathrm{~mm} \mathrm{Hg}$ and/or diastolic blood pressure $\geq 90 \mathrm{~mm}$ $\mathrm{Hg} .{ }^{27}$ Hypotension was defined as systolic blood pressure $<90 \mathrm{~mm} \mathrm{Hg}$ and/or diastolic blood pressure $<60 \mathrm{~mm} \mathrm{Hg} .{ }^{27}$ Hypertension and hypotension were defined as abnormal blood pressure. Waist circumference was measured to the nearest $0.1 \mathrm{~cm}$ by placing a non-stretch measuring tape horizontally around the participant's abdomen at the top of the iliac crest. Hip circumference was assessed at the point of maximum circumference over the buttocks, with the measuring tape held horizontally and touching the surface of light clothing. The waist:hip ratio (WHR) was calculated by dividing the waist circumference by the hip circumference. A WHR $>0.9$ in men or $>0.8$ in women was defined as abnormal. ${ }^{28}$

\section{HRQoL assessment}

HRQoL was assessed using the Medical Outcomes Study 36-Item Short Form Health Survey (SF-36) ${ }^{29}$ The SF-36 health survey questionnaire has been translated and validated in Chinese, and the Chinese version of the SF-36 has been proven to be reliable and valid in an elderly population. ${ }^{30}$ The SF-36 has been widely used to compare the quality of life of people with different diseases, ${ }^{31}{ }^{32}$ as well as among people who are disease-free. ${ }^{33}$ It contains 36 items grouped into eight main domains that constitute the two main components: physical health component and mental health component. The physical health section includes four parts: physical functioning, role-physical, bodily pain and general health, while vitality, social functioning, role-emotional and mental health are included in the mental health component. The eight domains were scored from 0 to 100 indicating worst to best possible health. All scores were further summarised and standardised into the physical component summary score (PCS) and the mental component summary score (MCS) according to American norms to allow for international comparisons. ${ }^{34}$

\section{Physical activity assessment}

The International Physical Activity Questionnaire-long version (IPAQ) was used to assess physical activity. The IPAQ has been translated and validated in different languages, including Chinese, and the Chinese version of the IPAQ has been shown to be an appropriate physical activity assessment in the Chinese population. ${ }^{35}$ The IPAQ-long version assesses a subject's physical activity in the last week in four domains with a minimum duration of $10 \mathrm{~min}$ per bout. It also identifies the frequency and time spending on three specific intensities of physical activity, namely walking, moderate and vigorous. The metabolic equivalent (MET) values were used for measurements. The patient's total physical activity MET-min/week was calculated by the sum of the walking, moderate and vigorous intensity activity scores. Based on the public health guidelines ${ }^{36}$ and recommended thresholds ${ }^{37}$ subjects were categorised as 'active' if they achieved $\geq 600 \mathrm{MET}$-min/week (equal to $\geq 150 \mathrm{~min} /$ week of moderate activity) and those who achieved less were considered to be 'inactive'.

\section{Statistical analysis}

Descriptive analyses were performed considering absolute frequency and relative percentage. Data were described as $\mathrm{n}(\%)$ for categorical variables and mean $\pm \mathrm{SD}$ or median $\left(\mathrm{P}_{25}-\mathrm{P}_{75}\right)$ for numerical variables. The mean $( \pm \mathrm{SD})$ PCS and MCS scores of HRQoL and their 95\% CIs were also calculated. The $\mathrm{X}^{2}$ test for categorical variables and independent sample t-test for normal distribution continuous variables were used to compare the differences between the physically active group and the physically inactive group. The t-test or one-way analysis of variance was used to identify the differences in PCS and MCS scores depending on different independent variables. The MannWhitney U test or Kruskal-Wallis test was used to identify the differences in total physical activity score depending on different variables. If necessary, the Nemenyi test for non-normal distribution and the Student-Newman-Keuls method for normal distribution were used to identify differences within groups. 
The Spearman's rank correlation coefficient test was done to explore the magnitude and relationships between variables that potentially influenced HRQoL. General linear models of multivariate analysis of covariance (MANCOVA) were used to test differences in HRQoL (ie, PCS and MCS) between the physically active and inactive groups. Physically inactive was coded as 0 and active was coded as 1 . Sociodemographic and anthropometric variables were treated as possible covariates. A significant MANCOVA was followed by univariate $F$-tests using the Wilks' $\lambda$ statistic. Linear independent pairwise comparisons were analysed to examine the magnitude of the difference in the mean scores of the dependent variables. Effect sizes (d) were computed by dividing the difference in means between groups by the pooled SD and were interpreted as small $(\mathrm{d}=0.20)$, medium $(\mathrm{d}=0.50)$ or large $(\mathrm{d}=0.80) .{ }^{38}$ Analyses in this study were performed by SPSS V.19.0.

\section{RESULTS}

\section{Characteristics of study subjects}

A total of 461 elderly individuals had pre-diabetes, and the prevalence of pre-diabetes was $21.5 \%$ (461/2144). Ultimately, 434 of these individuals were included in this study. The average age of all participants was $69.4 \pm 6.4$ years. A majority of the subjects were female, married and completed 1-6 years of education. More than $90 \%$ of elderly people with pre-diabetes had no history of hyperglycaemia and no family history of diabetes. The average BMI was $23.7 \pm 3.6 \mathrm{~kg} / \mathrm{m}^{2}$. Participants reported a mean waist circumference of $84.9 \pm 9.4 \mathrm{~cm}$ and a mean hip circumference of $92.0 \pm 10.4 \mathrm{~cm}$.

According to their IPAQ scores, $252(58.1 \%)$ were physically inactive and $182(41.9 \%)$ were physically active. There were significant differences in chronic disease, BMI, waist circumference and WHR between the physically active and inactive groups. Physically inactive subjects were those who had at least one chronic disease, higher BMI, higher waist circumference and higher WHR (all $\mathrm{P}<0.05)$. The descriptive characteristics of elderly subjects with pre-diabetes are shown in table 1.

\section{HRQOL score}

Individuals with pre-diabetes reported a mean $( \pm S D)$ PCS score of $42.1 \pm 10.2$ and a mean $( \pm \mathrm{SD})$ MCS score of $46.4 \pm 8.9$. The means and their 95\% CIs for both physical and mental component scores according to sociodemographic and physiological features are shown in table 2. Neither component scores showed a statistical difference for the variables of family history of diabetes, smoking, alcohol drinking or blood pressure (all $\mathrm{P}>0.05$ ). For the physical component, there were significant statistical differences in age, history of hyperglycaemia, history of chronic disease, BMI and WHR (all $\mathrm{P}<0.05$ ). The PCS scores were lower among people who were older and had a history of hyperglycaemia, at least one kind of chronic disease, abnormal WHR and higher BMI. For the mental component, there were statistically significant differences in gender, education and marital status (all $\mathrm{P}<0.05)$. Individuals who were female, completed more education and were married had higher scores on the mental component of HRQoL.

\section{IPAQ score}

The total physical activity scores of individuals with pre-diabetes measured by the IPAQ are shown in table 3 . Together, they reported a median total physical activity of 524.0 MET-min/week. Individuals with pre-diabetes who were physically active reported a median total physical activity of 832.5 MET-min/week. Individuals with pre-diabetes who were physically inactive reported a median total physical activity of $120.0 \mathrm{MET}$-min/week. The total physical activity score was significantly different in terms of gender, history of hyperglycaemia, other chronic disease and smoking through non-parametric tests (all $\mathrm{P}<0.05)$. Participants who were male, had no history of hyperglycaemia, no chronic disease and no smoking reported higher total MET values compared with those who were female and had a history of hyperglycaemia, chronic disease and smoking.

\section{Association between physical activity and HRQoL}

Correlations between HRQoL, sociodemographics and the health characteristics of individuals with pre-diabetes are presented in table 4. Spearman's correlation coefficients $(r)$ indicated that PCS was significantly correlated with physical activity $(\mathrm{r}=0.209, \mathrm{P}<0.01)$ and chronic disease $(\mathrm{r}=-0.133, \mathrm{P}<0.01)$, whereas MCS was significantly correlated with gender $(\mathrm{r}=0.196, \mathrm{P}<0.01)$. Physical activity was significantly correlated with gender $(\mathrm{r}=0.112$, $\mathrm{P}<0.05)$, smoking $(\mathrm{r}=-0.093, \mathrm{P}<0.05)$ and chronic disease $(r=0.134, P<0.01)$. Variables with significant $P$ values in the correlation analysis and thought to be important influencing factors of HRQoL were entered into the multivariate model.

With HRQoL entered as the dependent variable and physical activity (as a binary variable) entered as the independent variable, the overall multivariate analysis of covariance (MANCOVA) was significant (Wilks' $\lambda=0.956, F($ $2,431)=10.03, \mathrm{P}<0.001)$. Follow-up univariate $F$ statistics indicated significant differences only for PCS ( $F=19.49$, $\mathrm{P}<0.001)$. A linear independent pairwise comparison indicated that those who were physically active reported significantly higher scores on the PCS $\left(\mathrm{M}_{\text {diff }}=5.6, \mathrm{P}<0.001\right.$, effective size $(\mathrm{ES})=0.55)$ than those who were physically inactive. After adjusting for the covariates of age, gender, marital status, education, smoking, chronic disease, BMI and WHR, the overall MANCOVA model was significant (Wilks' $\lambda=0.962, F(2,423)=8.44, \mathrm{P}<0.001$ ). A linear independent pairwise comparison indicated that those who were physically active still reported a significantly higher score in the PCS $\left(\mathrm{M}_{\text {diff }}=5.2, \mathrm{P}<0.001, \mathrm{ES}=0.47\right)$ than those who were physically inactive. Results are shown in table 5 .

\section{DISCUSSION}

This study showed a high prevalence $(21.5 \%)$ of pre-diabetes among the rural elderly, which is similar to the 
Table 1 Characteristics of elderly individuals with pre-diabetes

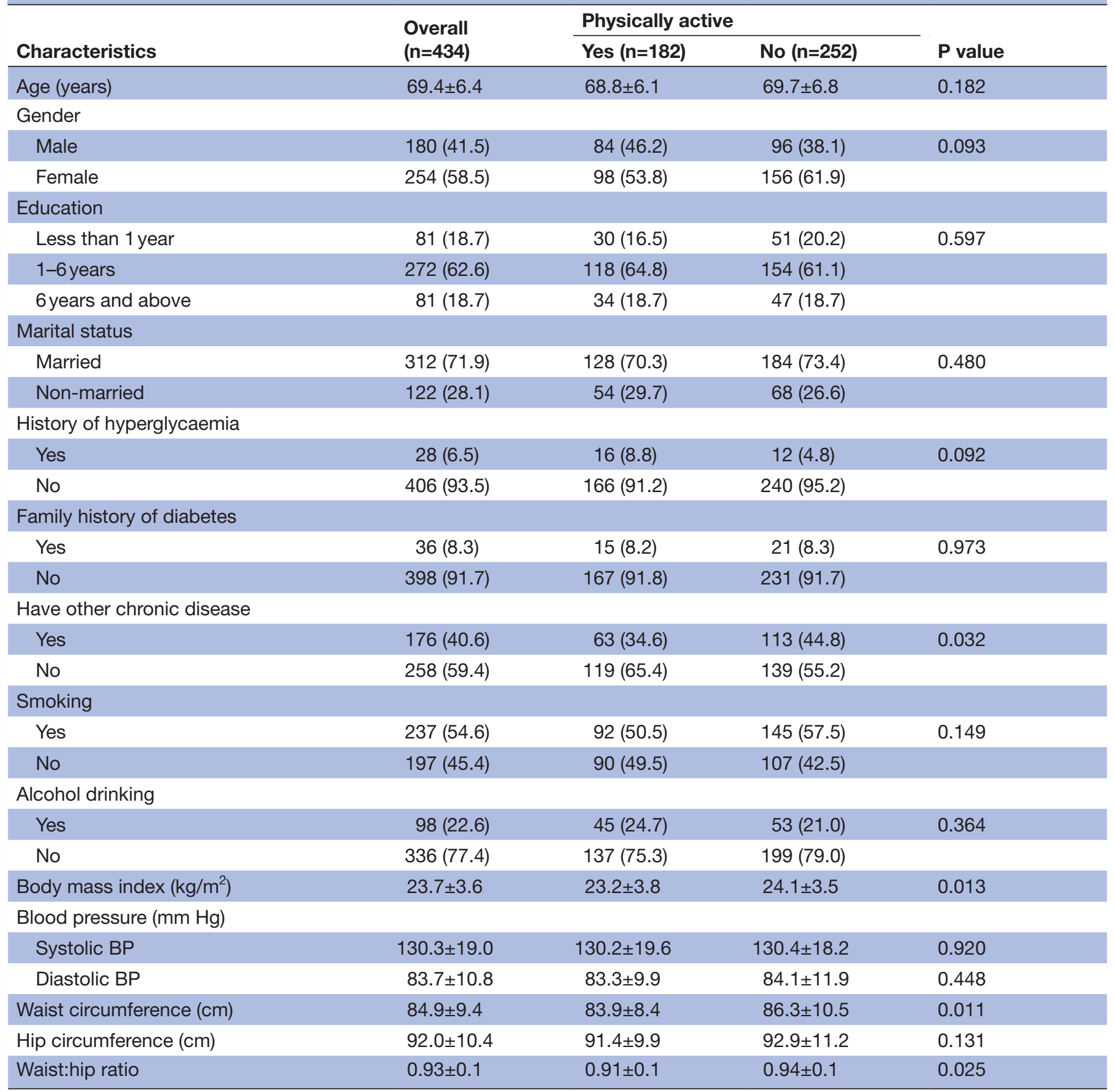

Data were described as $\mathrm{n}(\%)$ or mean \pm SD; t-test was used for continuous variables and $\chi^{2}$ test was used for categorical variables. BP, blood pressure.

findings of an earlier study. ${ }^{39}$ As previously reported and discussed, the prevalence of pre-diabetes is rapidly increasing in rural areas of China, which means there is a need to pay more attention to prevention. ${ }^{25}$

According to this study, the elderly with pre-diabetes in rural areas reported a median physical activity of 524 MET-min/week, and $58.1 \%$ of the elderly with pre-diabetes were physically inactive, while $41.9 \%$ of them were physically active. This is similar to other studies. ${ }^{4041}$ Taylor et $a t^{40}$ reported that $38 \%$ of people with pre-diabetes were physically active. In the Diabetes Prevention Program
(DPP) study, ${ }^{41}$ the baseline median leisure-time physical activity was 534 MET-min/week. However, it was lower than the Diabetes Prevention Study, which reported that at least $50 \%$ of participants were considered physically active ${ }^{42}$ more than a diabetic population, which reported only $32 \%$ of people with diabetes were physically active using current physical activity guidelines. ${ }^{43}$ On one hand, this may be that the mean age of our study subjects was much higher than these two studies. ${ }^{4243}$ On the other hand, significant chronic conditions, functional limitations and lower fitness levels should also be considered. 
Open Access

Table 2 HRQoL score measured by SF-36 (physical and mental components)

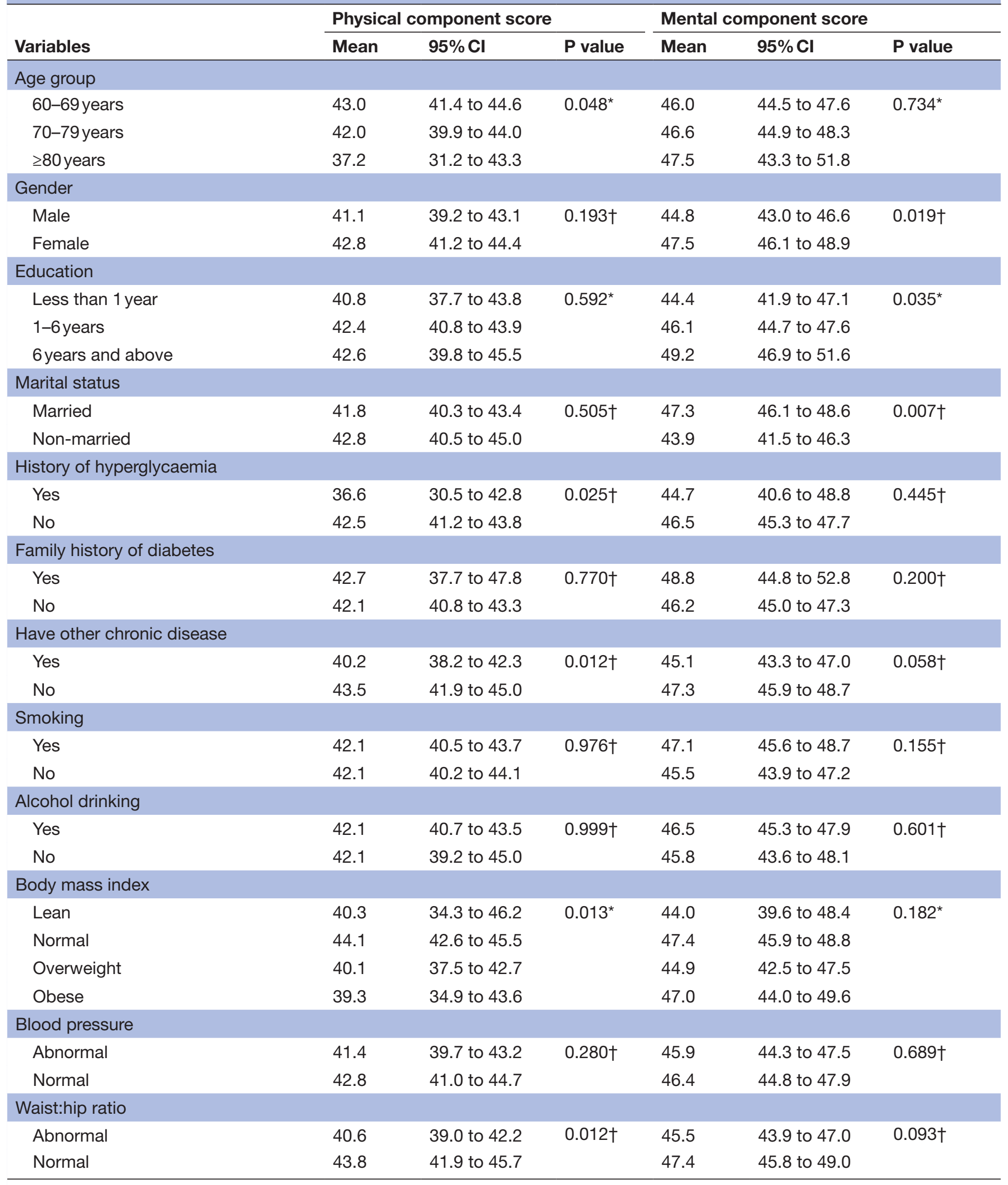

${ }^{\star}$ ANOVA test for trend.

†P values were determined by t-test.

ANOVA, analysis of variance; HRQoL, health-related quality of life; SF-36, Medical Outcomes Study 36-Item Short Form Health Survey. 
Table 3 Total physical activity score of pre-diabetes measured by IPAQ-long version

\begin{tabular}{|c|c|c|c|}
\hline Variables & $\begin{array}{l}\text { Total physical activity } \\
\text { (MET-min/week) }\end{array}$ & $\mathbf{Z}$ value & $P$ value \\
\hline \multicolumn{4}{|l|}{ Age group } \\
\hline 70-79years & $465.0(0-745.0)$ & & \\
\hline$\geq 80$ years & $386.0(60.0-693.0)$ & & \\
\hline Female & $462.0(0-726.5)$ & & \\
\hline \multicolumn{4}{|l|}{ Education } \\
\hline Less than 1 year & $465.0(0-697.0)$ & 1.45 & $0.485^{\star}$ \\
\hline 1-6years & $560.0(0-780.0)$ & & \\
\hline Non-married & $542.0(0-845.0)$ & & \\
\hline \multicolumn{4}{|c|}{ History of hyperglycaemia } \\
\hline Yes & $500.0(0-772.0)$ & 2.21 & $0.027 \dagger$ \\
\hline No & $682.0(467.5-875.5)$ & & \\
\hline \multicolumn{4}{|c|}{ Family history of diabetes } \\
\hline Yes & $560.0(252.0-769.5)$ & 0.54 & $0.592 \dagger$ \\
\hline No & $512.0(0-780.0)$ & & \\
\hline \multicolumn{4}{|c|}{ Have other chronic disease } \\
\hline Yes & $579.0(90.0-792.0)$ & 1.36 & $0.174 \dagger$ \\
\hline No & $495.0(0-760.5)$ & & \\
\hline \multicolumn{4}{|l|}{ Body mass index (BMI) } \\
\hline Lean & $555.0(0-750.0)$ & 6.88 & $0.076^{\star}$ \\
\hline Normal & $560.0(0-791.0)$ & & \\
\hline Overweight & $415.0(0-715.5)$ & & \\
\hline Obese & $345.0(0-598.0)$ & & \\
\hline \multicolumn{4}{|l|}{ Blood pressure } \\
\hline Abnormal & $560.0(0-785.5)$ & 1.33 & $0.184 \dagger$ \\
\hline Normal & $462.0(0-735.0)$ & & \\
\hline \multicolumn{4}{|l|}{ Waist:hip ratio } \\
\hline Abnormal & $487.5(0-792.5)$ & 0.37 & $0.715 \dagger$ \\
\hline Normal & $546.0(0-755.0)$ & & \\
\hline
\end{tabular}

Data were described as median $\left(\mathrm{P}_{25}-\mathrm{P}_{75}\right)$.

${ }^{*} \mathrm{P}$ value was determined by Kruskal-Wallis test.

$\dagger P$ value was determined by Mann-Whitney $U$ test.

IPAQ, International Physical Activity Questionnaire; MET, metabolic equivalent. 
Table 4 Bivariate Spearman's correlations between health-related quality of life, sociodemographics and health characteristics

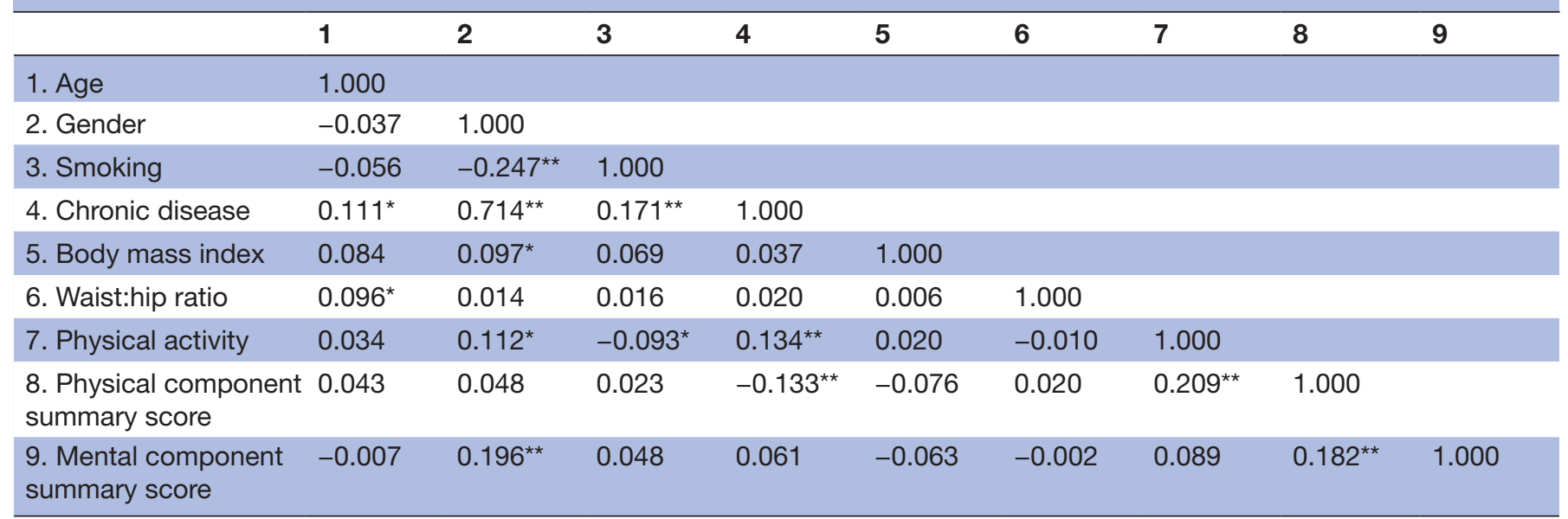

Significant correlation at ${ }^{*} \mathrm{P}<0.05$ and ${ }^{*} \mathrm{P}<0.01$ (two-tailed).

Body mass index in $\mathrm{kg} / \mathrm{m}^{2}$. Physical activity in total metabolic equivalent-min/week.

In addition, the US public health guidelines for physical activity state that all adults should achieve a minimum of moderate-intensity physical activity for $30 \mathrm{~min}$ on at least 5 days each week or a minimum of 20 min of vigorous-intensity physical activity on at least 3 days each week to promote health. ${ }^{3644}$ Participants of the physically active group in this study attained $600 \mathrm{MET}$-min/week, which was equal to $150 \mathrm{~min} /$ week of moderate activity, indicating that they achieved the public health guidelines for physical activity.

Although the effect of physical activity on HRQoL has been widely discussed among some populations in the previous literature, ${ }^{17} 2045-50$ there are few studies that explore the association between physical activity and HRQoL in individuals with pre-diabetes, and especially there is a lack of research among the elderly with pre-diabetes. To our knowledge, this is the first study to investigate the influence of physical activity on HRQoL in the elderly with pre-diabetes. In support of our hypotheses, we found that physical activity was associated with HRQoL among elderly individuals with pre-diabetes, after adjusting for several HRQoL correlates. More specifically, physically active participants reported higher PCS scores than physically inactive participants. These results are generally consistent with previous research that targeted different populations, ${ }^{4051}$ indicating that there are positive associations between physical activity and HRQoL. Taylor $e t a l^{40}$ found that people with pre-diabetes who were physically active reported 2.7 points higher on physical health and 3.0 points higher on the mental health component of HRQoL than those physically inactive after adjusting for many covariates. Häkkinen $e t a \tilde{l}^{\tilde{1}}$ found that individuals at 'high risk' of developing type 2 diabetes who engaged in physical activity two or more times per week had a better perception of general health and physical functioning compared with those not engaging in physical activity, although Ibrahim $e t a \tilde{l}^{2}$ found that physical activity was not a strong predictor of HRQoL among individuals with pre-diabetes. This may be that the authors stratified by BMI when analysing the association between physical activity and HRQoL, and the small sample size in the BMI subgroup may not have adequate power to produce significant associations between physical activity and HRQoL. If a change of $5-10$ points in the SF-36 scores has been suggested as being clinically significant for clinical populations with a variety of illnesses, ${ }^{53}$ the

Table 5 Association between physical activity and health-related quality of life (physical and mental components)

\begin{tabular}{|c|c|c|c|c|c|c|c|}
\hline \multirow[b]{2}{*}{ Variables } & \multicolumn{2}{|c|}{ Physically active } & \multicolumn{2}{|c|}{ Physically inactive } & \multicolumn{3}{|l|}{ Difference } \\
\hline & Mean & SE & Mean & SE & $M_{\text {diff }}(95 \% \mathrm{Cl})$ & ES(d) & $P$ value \\
\hline \multicolumn{8}{|c|}{ Crude analysis (Wilks' $\lambda=0.956, F(2,431)=10.03, P<0.001)$} \\
\hline PCS & 45.3 & 0.93 & 39.8 & 0.84 & $5.6(3.2$ to 8.1$)$ & 0.55 & $<0.001$ \\
\hline MCS & 47.3 & 0.78 & 45.7 & 0.80 & $1.6(-0.7$ to 3.8$)$ & 0.21 & 0.173 \\
\hline \multicolumn{8}{|c|}{ Adjusted analysis (Wilks' $\lambda=0.962, F(2,423)=8.44, \mathrm{P}<0.001)^{\star}$} \\
\hline PCS & 45.1 & 0.97 & 39.9 & 0.83 & $5.2(2.5$ to 7.6$)$ & 0.47 & $<0.001$ \\
\hline MCS & 47.4 & 0.87 & 45.6 & 0.74 & $1.7(-0.5$ to 4.1$)$ & 0.26 & 0.127 \\
\hline
\end{tabular}

*Adjusted for age, gender, marital status, education, smoking, chronic disease, body mass index and waist:hip ratio.

$\mathrm{ES}(\mathrm{d})$, mean difference/pooled SD; $\mathrm{M}_{\text {diff }}$, mean difference; MCS, mental component summary score; PCS, physical component summary score. 
differences in this study are important and meaningful, especially on the PCS of HRQoL, since they are observed in a population with pre-diabetes.

Another interesting finding of our study was that only the physical component score of HRQoL showed differences between the physically active and inactive groups. This result is consistent with some studies. ${ }^{55} 56$ Nakamura et $a \tilde{l}^{55}$ found that the level and intensity of physical activity were not associated with the mental health domain for women. Morimoto et $a t^{45}$ found that women who performed physical activity had higher HRQoL in almost all domains except for mental health and social function, and other two studies have shown that the physical and mental aspects of HRQoL were associated with physical activity. ${ }^{57}$ However, the relationship between physical activity and the mental component of HRQoL is not entirely clear. First, the association between physical activity and the mental health domain may be mediated through differences in maximal oxygen uptake and body fat percentage, or due to emotional health. ${ }^{59}{ }^{60}$ Second, these differences may be related to different categorisations of physical activity, different instruments to assess HRQoL and the evaluation of different ages and genders.

The third interesting finding in this study was that individuals with pre-diabetes showed lower physical component scores compared with the mental health component scores, which was consistent with other studies. ${ }^{40}{ }^{52}$ This may be because some of the elderly with pre-diabetes have difficulties in physical activities due to their sick body. Study has shown that chronic diseases have a stronger effect on reducing the physical function than psychological function. ${ }^{61}$ In this elderly population with pre-diabetes, more than $40.0 \%$ had at least one chronic disease and majority were overweight or obese, and studies have reported that many individuals with pre-diabetes were uncertain about their disease, and they considered pre-diabetes to be not serious and easily accepted.$^{6263}$

Results from this study provided evidence for differences in HRQoL among the elderly with pre-diabetes compared with the general population. Individuals with pre-diabetes reported a mean PCS score of $42.1 \pm 10.2$ and a mean MCS score of $46.4 \pm 8.9$, suggesting that their health status was slightly lower compared with population norms $(\mathrm{P}<0.05) .{ }^{34}$ Many studies also identified that individuals with IGT were more likely to report lower HRQoL scores compared with those with normal glucose tolerance (NGT) ${ }^{1263}$ These reports suggest that individuals with pre-diabetes may receive HRQoL benefits from related interventions. However, individuals with pre-diabetes who are physically active have better PCS scores than those who were physically inactive, suggesting that physical activity may be adapted to HRQoL intervention for pre-diabetes. If the positive health benefits of physical activity are well perceived, it is important to plan public health interventions designed to promote physical activity and decrease sedentary lifestyle. Moreover, based on physical activity, lifestyle intervention can reduce the incidence of diabetes among individuals with pre-diabetes. ${ }^{60}$ But for the elderly, the intensity of activity should take into account muscle fitness and cardiopulmonary endurance; thus, activities focused on maintaining or increasing flexibility are recommended. ${ }^{64}$

Our study has several limitations. First, our study used a cross-sectional study design, which did not allow a causal relationship to be established. Thus, future studies need to conduct both longitudinal and randomised controlled trial designs to garner a deeper understanding of the relationship between physical activity and HRQoL. Second, self-administered questionnaires were used to assess physical activity and HRQoL; therefore, an inaccurate estimation of the physical activity and HRQoL and recall bias were unavoidable. However, this limitation was minimised because both instruments used in this study are valid and reliable. ${ }^{30}$ Third, we did not consider the specific variation regarding level and intensity as well as domain-specific physical activity on HRQoL, even though different intensities and domains of physical activity have different influences on HRQoL. ${ }^{565}$ Considering the large population of elderly with pre-diabetes and suitably using the IPAQ-long version and the SF-36 assessment tool, the results of this study are generalisable.

\section{CONCLUSIONS}

In summary, elderly individuals with pre-diabetes in the rural Hunan Province of China reported a relatively lower HRQoL score. Only $41.9 \%$ of them reported a total physical activity score higher than 600 MET-min/ week. Rural elderly with pre-diabetes who were physically active reported a higher HRQoL score only on the physical component compared with those who were physically inactive. Further studies need to be conducted to garner a deeper understanding of the relationship between physical activity and HRQoL.

Acknowledgements We thank all the participants very much for their collaboration.

Contributors $\mathrm{HX}$ had the original idea for the study and LQ carried out the design. ZH, FG and YY collected the data and information as investigators. LQ and LT completed the statistical analyses and drafted the manuscript. LQ and BL checked and revised the manuscript. All authors read and approved the final manuscript.

Funding Thank you a lot for the support of the Teachers Research Found of Central South University (2013JSJJ034) and the Central South University Graduate Student Independent Exploration Innovation Project (N0.2013zzts286).

Competing interests None declared.

Patient consent Obtained.

Ethics approval The study was approved by the Medical Ethics Committee of Central South University (Changsha, China; Identification Code: CTXY-150002-7; 27 February 2015).

Provenance and peer review Not commissioned; externally peer reviewed. Data sharing statement No additional data are available.

Open Access This is an Open Access article distributed in accordance with the Creative Commons Attribution Non Commercial (CC BY-NC 4.0) license, which permits others to distribute, remix, adapt, build upon this work non-commercially, and license their derivative works on different terms, provided the original work is 
properly cited and the use is non-commercial. See: http://creativecommons.org/ licenses/by-nc/4.0/

(C) Article author(s) (or their employer(s) unless otherwise stated in the text of the article) 2018. All rights reserved. No commercial use is permitted unless otherwise expressly granted.

\section{REFERENCES}

1. Alberti KG, Zimmet PZ. Definition, diagnosis and classification of diabetes mellitus and its complications. Part 1: diagnosis and classification of diabetes mellitus provisional report of a WHO consultation. Diabet Med 1998;15:539-53.

2. Forouhi NG, Luan J, Hennings S, et al. Incidence of Type 2 diabetes in England and its association with baseline impaired fasting glucose: the Ely study 1990-2000. Diabet Med 2007;24:200-7.

3. Nathan DM, Davidson MB, DeFronzo RA, et al. Impaired fasting glucose and impaired glucose tolerance: implications for care. Diabetes Care 2007;30:753-9.

4. Yang W, Lu J, Weng J, et al. Prevalence of diabetes among men and women in China. N Engl J Med 2010;362:1090-101.

5. Tuomilehto J, Lindström J, Eriksson JG, et al. Prevention of type 2 diabetes mellitus by changes in lifestyle among subjects with impaired glucose tolerance. N Engl J Med 2001;344:1343-50.

6. Hu Z, Qin L, Xu H. One-Year Results of a Synthetic Intervention Model for the Primary Prevention of T2D among Elderly Individuals with Prediabetes in Rural China. Int $J$ Environ Res Public Health 2017:14:417.

7. WHO. The World Health Organization Quality of Life assessment (WHOQOL): position paper from the World Health Organization. Soc Sci Med 1995;41:1403-9.

8. Schwimmer JB, Burwinkle TM, Varni JW. Health-related quality of life of severely obese children and adolescents. JAMA 2003;289:1813-9.

9. Jayasinghe UW, Harris MF, Parker SM, et al. The impact of health literacy and life style risk factors on health-related quality of life of Australian patients. Health Qual Life Outcomes 2016;14:68.

10. Fone D, Dunstan F, Lloyd K, et al. Does social cohesion modify the association between area income deprivation and mental health? A multilevel analysis. Int J Epidemiol 2007;36:338-45.

11. Keles H, Ekici A, Ekici M, et al. Effect of chronic diseases and associated psychological distress on health-related quality of life. Intern Med J 2007;37:6-11.

12. Tapp RJ, Dunstan DW, Phillips $P$, et al. Association between impaired glucose metabolism and quality of life: results from the Australian diabetes obesity and lifestyle study. Diabetes Res Clin Pract 2006;74:154-61.

13. Ghorbani A, Ziaee A, Esmailzadehha N, et al. Association between health-related quality of life and impaired glucose metabolism in Iran: the Qazvin Metabolic Diseases Study. Diabet Med 2014;31:754-8.

14. Hunger $M$, Holle R, Meisinger $\mathrm{C}$, et al. Longitudinal changes in health-related quality of life in normal glucose tolerance, prediabetes and type 2 diabetes: results from the KORA S4/F4 cohort study. Qual Life Res 2014;23:2515-20.

15. Alonso J, Ferrer M, Gandek B, et al. Health-related quality of life associated with chronic conditions in eight countries: Results from the International Quality of Life Assessment (IQOLA) Project. Quality of Life Research 2004;13:283-98.

16. Ethgen $\mathrm{O}$, Bruyère $\mathrm{O}$, Richy $\mathrm{F}$, et al. Health-related quality of life in total hip and total knee arthroplasty. A qualitative and systematic review of the literature. J Bone Joint Surg Am 2004;86-A:963-74.

17. Halaweh H, Willen C, Grimby-Ekman A, et al. Physical Activity and Health-Related Quality of Life Among Community Dwelling Elderly. J Clin Med Res 2015;7:845-52.

18. Cho KO. The Positive Effect of Physical Activity on Health and Health-related Quality of Life in Elderly Korean People-Evidence from the Fifth Korea National Health and Nutrition Examination Survey. J Lifestyle Med 2014;4:86-94.

19. Eckert K. Impact of physical activity and bodyweight on healthrelated quality of life in people with type 2 diabetes. Diabetes Metab Syndr Obes 2012;5:303-11.

20. Bize R, Johnson JA, Plotnikoff RC. Physical activity level and healthrelated quality of life in the general adult population: a systematic review. Prev Med 2007;45:401-15.

21. Gillison FB, Skevington SM, Sato A, et al. The effects of exercise interventions on quality of life in clinical and healthy populations; a meta-analysis. Soc Sci Med 2009;68:1700-10.

22. Floegel TA, Perez GA. An integrative review of physical activity/ exercise intervention effects on function and health-related quality of life in older adults with heart failure. Geriatr Nurs 2016;37:340-7.
23. Eaglehouse YL, Schafer GL, Arena VC, et al. Impact of a communitybased lifestyle intervention program on health-related quality of life. Qual Life Res 2016;25:1903-12.

24. Lee PH, Chang WY, Liou TH, et al. Stage of exercise and healthrelated quality of life among overweight and obese adults. J Adv Nurs 2006;53:295-303.

25. Qin L, Xu H. A cross-sectional study of the effect of health literacy on diabetes prevention and control among elderly individuals with prediabetes in rural China. BMJ Open 2016;6:e011077.

26. Wu Y. Overweight and obesity in China. BMJ 2006;333:362-3.

27. Liu LS. Writing Group of 2010 Chinese Guidelines for the Management of Hypertension. [2010 Chinese guidelines for the management of hypertension]. Zhonghua Xin Xue Guan Bing Za Zhi 2011;39:701-43.

28. Obesity in Asia Collaboration. Is central obesity a better discriminator of the risk of hypertension than body mass index in ethnically diverse populations? J Hypertens 2008;26:169-77.

29. Ware JE, Gandek B. Overview of the SF-36 Health Survey and the International Quality of Life Assessment (IQOLA) Project. J Clin Epidemiol 1998;51:903-12.

30. Zhou B, Chen K, Wang J, et al. Reliability and validity of a ShortForm Health Survey Scale(SF-36), Chinese version used in an elderly population of Zhejiang province in China. Chin J Epidemiol 2008;29:1193-8.

31. Chen HM, Tu YH, Chen CM. Effect of Continuity of Care on Quality of Life in Older Adults With Chronic Diseases: A Meta-Analysis. Clin Nurs Res 2017;26:266-84.

32. Kiadaliri AA, Najafi B, Mirmalek-Sani M. Quality of life in people with diabetes: a systematic review of studies in Iran. $J$ Diabetes Metab Disord 2013;12:54.

33. Alonso J, Ferrer M, Gandek B, et al. Health-related quality of life associated with chronic conditions in eight countries: results from the International Quality of Life Assessment (IQOLA) Project. Qual Life Res 2004;13:283-98.

34. Ware JE, Kosinski M, Keller S. SF-36 physical and mental health summary scales: a user's manual. 5th edn. Boston, MA: Health Assessment Lab. New England Medical Center, 1994.

35. Qu N, Li K. Study on the reliability and validity of international physical activity questionnaire (Chinese version IPAQ). Chin J Epidemiol 2004;25:265-7.

36. Pate RR, Pratt M, Blair SN, et al. Physical activity and public health. A recommendation from the Centers for Disease Control and Prevention and the American College of Sports Medicine. JAMA 1995;273:402-7.

37. Brown WJ, Bauman AE. Comparison of estimates of population levels of physical activity using two measures. Aust N Z J Public Health 2000;24:520-5.

38. Cohen J. A power primer. Psychol Bull 1992;112:155-9.

39. Xu Y, Wang L, He J, et al. Prevalence and control of diabetes in Chinese adults. JAMA 2013;310:948-59.

40. Taylor LM, Spence JC, Raine K, et al. Physical activity and healthrelated quality of life in individuals with prediabetes. Diabetes Res Clin Pract 2010;90:15-21.

41. Delahanty LM, Conroy MB, Nathan DM. Psychological predictors of physical activity in the diabetes prevention program. J Am Diet Assoc 2006;106:698-705.

42. Lindström J, Louheranta A, Mannelin M, et al. The Finnish Diabetes Prevention Study (DPS): Lifestyle intervention and 3-year results on diet and physical activity. Diabetes Care 2003;26:3230-6.

43. Thiel DM, Al Sayah F, Vallance JK, et al. Association between Physical Activity and Health-Related Quality of Life in Adults with Type 2 Diabetes. Can J Diabetes 2017;41:58-63.

44. Haskell WL, Lee IM, Pate RR, et al. Physical activity and public health: updated recommendation for adults from the American College of Sports Medicine and the American Heart Association. Med Sci Sports Exerc 2007;39:1423-34.

45. Morimoto T, Oguma Y, Yamazaki S, et al. Gender differences in effects of physical activity on quality of life and resource utilization. Qual Life Res 2006;15:537-46.

46. Wendel-Vos GC, Schuit AJ, Tijhuis MA, et al. Leisure time physical activity and health-related quality of life: cross-sectional and longitudinal associations. Qual Life Res 2004;13:667-77.

47. Tessier S, Vuillemin A, Bertrais S, et al. Association between leisuretime physical activity and health-related quality of life changes over time. Prev Med 2007;44:202-8.

48. Brown DW, Balluz LS, Heath GW, et al. Associations between recommended levels of physical activity and health-related quality of life. Findings from the 2001 Behavioral Risk Factor Surveillance System (BRFSS) survey. Prev Med 2003;37:520-8.

49. Brown DW, Brown DR, Heath GW, et al. Associations between physical activity dose and health-related quality of life. Med Sci Sports Exerc 2004;36:890-6. 
50. Chyun DA, Melkus GD, Katten DM, et al. The association of psychological factors, physical activity, neuropathy, and quality of life in type 2 diabetes. Biol Res Nurs 2006;7:279-88.

51. Häkkinen A, Kukka A, Onatsu T, et al. Health-related quality of life and physical activity in persons at high risk for type 2 diabetes. Disabil Rehabil 2009;31:799-805.

52. Ibrahim N, Moy FM, Awalludin IA, et al. The health-related quality of life among pre-diabetics and its association with body mass index and physical activity in a semi-urban community in Malaysia--a cross sectional study. BMC Public Health 2014;14:298.

53. Newnham EA, Harwood KE, Page AC. Evaluating the clinical significance of responses by psychiatric inpatients to the mental health subscales of the SF-36. J Affect Disord 2007;98:91-7.

54. Samsa G, Edelman D, Rothman ML, et al. Determining clinically important differences in health status measures: a general approach with illustration to the Health Utilities Index Mark II. Pharmacoeconomics 1999;15:141-55.

55. Nakamura PM, Teixeira IP, Smirmaul BP, et al. Health related quality of life is differently associated with leisure-time physical activity intensities according to gender: a cross-sectional approach. Health Qual Life Outcomes 2014;12:98.

56. Jayasinghe UW, Harris MF, Taggart J, et al. Gender differences in health-related quality of life of Australian chronically-ill adults: patient and physician characteristics do matter. Health Qual Life Outcomes 2013;11:102.
57. Shibata A, Oka K, Nakamura Y, et al. Recommended level of physical activity and health-related quality of life among Japanese adults. Health Qual Life Outcomes 2007;5:64.

58. Vuillemin A, Boini S, Bertrais S, et al. Leisure time physical activity and health-related quality of life. Prev Med 2005;41:562-9.

59. Stewart KJ, Turner KL, Bacher AC, et al. Are fitness, activity, and fatness associated with health-related quality of life and mood in older persons? J Cardiopulm Rehabil 2003;23:115-21.

60. Stewart AL, Mills KM, Sepsis PG, et al. Evaluation of CHAMPS, a physical activity promotion program for older adults. Ann Behav Med 1997;19:353-61.

61. Cigolle CT, Langa KM, Kabeto MU, et al. Geriatric conditions and disability: the Health and Retirement Study. Ann Intern Med 2007;147:156-64.

62. Troughton J, Jarvis J, Skinner C, et al. Waiting for diabetes: perceptions of people with pre-diabetes: a qualitative study. Patient Educ Couns 2008;72:88-93.

63. Chittleborough CR, Baldock KL, Taylor AW, et al. Health status assessed by the SF-36 along the diabetes continuum in an Australian population. Qual Life Res 2006;15:687-94.

64. Nelson ME, Rejeski WJ, Blair SN, et al. Physical activity and public health in older adults: recommendation from the American College of Sports Medicine and the American Heart Association. Med Sci Sports Exerc 2007;39:1435-45.

65. Jurakić D, Pedišić Z, Greblo Z. Physical activity in different domains and health-related quality of life: a population-based study. Qual Life Res 2010;19:1303-9. 